\title{
Hemoglobin Enhances the Biological Activity of Synthetic and Natural Bacterial (Endotoxic) Virulence Factors: A General Principle
}

\author{
Jörg Howe ${ }^{1}$, Walter Richter ${ }^{2}$, Lynn Hawkins ${ }^{3}$, Manfred Rössle ${ }^{4}$, Christian Alexander, Karin \\ Fournier $^{5}$, Jean Pierre Mach ${ }^{5}$, Thierry Waelli ${ }^{6}$, Reginald M. Gorczynski ${ }^{7}$, Artur J. Ulmer ${ }^{1}$, Helmut \\ Brade $^{1}$, Alla Zamyatina ${ }^{8}$, Paul Kosma ${ }^{8}$, Ernst Th. Rietschel ${ }^{9}$ and Klaus Brandenburg ${ }^{1, *}$
}

\begin{abstract}
${ }^{1}$ Forschungszentrum Borstel, Leibniz-Zentrum für Medizin und Biowissenschaften, 23845 Borstel, Germany; ${ }^{2}$ FriedrichSchiller-Universität Jena, Elektronenmikroskopisches Zentrum, 07740 Jena, Germany; ${ }^{3}$ Eisai Research Institute, Discovery Chemistry, 4 Corporate Dr, Andover, MA 01810-2441, USA; ${ }^{4}$ European Molecular Biology Laboratory, Hamburg outstation, D-22603 Hamburg, Germany; ${ }^{5}$ Institute de Biochemie, Université de Lausanne, Lausanne, Switzerland; ${ }^{6}$ Clinique La Prairie, Montreux, Switzerland; ${ }^{7}$ Dep. of Surgery and Immunology, University Health Network, Toronto, Canada $;{ }^{8}$ Universität für Bodenkultur, Dep. für Chemie, 1190 Wien, Austria $;{ }^{9}$ Leibniz-Gemeinschaft, Schützenstr. $6 a, D$ 10117 Berlin, Germany
\end{abstract}

\begin{abstract}
Although hemoglobin ( $\mathrm{Hb})$ is mainly present in the cytoplasm of erythrocytes (red blood cells), lower concentrations of pure, cell-free $\mathrm{Hb}$ are released permanently into the circulation due to an inherent intravascular hemolytic disruption of erythrocytes. Previously it was shown that the interaction of $\mathrm{Hb}$ with bacterial endotoxins (lipopolysaccharides, LPS) results in a significant increase of the biological activity of LPS. There is clear evidence that the enhancement of the biological activity of LPS by $\mathrm{Hb}$ is connected with a disaggregation of LPS. From these findings one questions whether the property to enhance the biological activity of endotoxin, in most cases proven by the ability to increase the cytokine (tumor-necrosis-factor- $\alpha$, interleukins) production in human mononuclear cells, is restricted to bacterial endotoxin or is a more general principle in nature. To elucidate this question, we investigated the interaction of various synthetic and natural virulence (pathogenicity) factors with hemoglobin of human or sheep origin. In addition to enterobacterial R-type LPS a synthetic bacterial lipopeptide and synthetic phospholipid-like structures mimicking the lipid A portion of LPS were analysed. Furthermore, we also tested endotoxically inactive LPS and lipid A compounds such as those from Chlamydia trachomatis. We found that the observations made for endotoxically active form of LPS can be generalized for the other synthetic and natural virulence factors: In every case, the cytokine-production induced by them is increased by the addition of $\mathrm{Hb}$. This biological property of $\mathrm{Hb}$ is connected with its physical property to convert the aggregate structures of the virulence factors into one with cubic symmetry, accompanied with a considerable reduction of the size and number of the original aggregates.
\end{abstract}

\section{INTRODUCTION}

Bacterial lipopolysaccharides (LPS, endotoxins) are the major lipid components of the outer membrane of Gramnegative bacteria. They are anchored in the outer membrane by their hydrophobic lipid A portion and when released into the environment, are highly active in mammals. Experiments in many biological systems proved that the lipid A subunit is responsible for the endotoxicity [1]. The biological activities may be beneficial at low LPS concentrations, but pathophysiological at higher concentrations due to excessive cytokine production by cells of the immune system. This may lead to septic shock for which no successful anti-endotoxin therapies are presently available. LPS consists of a carbohydrate portion with varying lengths of oligo- or polysaccharide chains depending on the type of bacterial mutant, i.e., rough mutant LPS Re to Ra or smooth form LPS. The polysaccharide component is covalently linked to the hydrophobic anchor of LPS, or lipid A [2]. There are various endotoxin-binding proteins, which may have considerable bio-

*Address correspondence to this author at the Forschungszentrum Borstel, Leibniz-Zentrum für Medizin und Biowissenschaften, 23845 Borstel, Germany; E-mail: kbranden@fz-borstel.de logical importance. The binding of LPS to these proteins has been characterized in recent years, but frequently the processes involved in binding, in particular in the light of the modifications of the LPS-induced responses [3, 4] are not well understood. Hemoglobin $(\mathrm{Hb})$, the four subunit globular oxygen-carrying protein of vertebrates and some invertebrates, is present in the red blood cells specialized for oxygen transport, which contain a high concentration of hemoglobin in their cytoplasm. Cell-free solutions of $\mathrm{Hb}$ are potentially useful for resuscitation, elective surgery, as well as in adjunctive therapeutical treatment of shock, cancer therapy, sickle cell anaemia, coronary balloon angioplasty, stroke and myocardial ischemia $[5,6]$. Levin and Roth have found in their pioneering investigations $[7,8]$, that the interaction of $\mathrm{Hb}$ with LPS results in a significant increase of the biological activity of LPS, and the lethal toxicity of LPS for rodents was enhanced in the presence of $\mathrm{Hb}$ [9]. This may lead to severe problems in the case of blood substituents which may be contaminated with LPS. We have shown that the enhancement of the biological response was associated with a conversion of LPS aggregates into cubic structures [10], accompanied by reduction of the aggregate sizes (disaggregation $[11,12])$. Furthermore we found that an inactive pentaacylated LPS or lipid A is converted into an active "en- 
dotoxic conformation' by the addition of $\mathrm{Hb}$ [13]. Here, in continuation of previous work we have extended our investigations to LPS with longer carbohydrate chain as well as to different pathogenicity factors, which have been shown to exert endotoxin-like effects.

\section{MATERIALS AND METHODS}

\section{Lipids and Reagents}

$\mathrm{Pam}_{3} \mathrm{CSK}_{4}$ was synthesized and analysed by EMC microcollections $\mathrm{GmbH}$ according to published procedures [14].

The phospholipid-like structure ER-803022 was synthesized at Eisai Research Institute of Boston, Andover, MA;. The structure was confirmed by ${ }^{1} \mathrm{H}-,{ }^{13} \mathrm{C}$-, and ${ }^{31} \mathrm{P}-\mathrm{NMR}$, mass spectrometry, and elemental analysis.

Lipopolysaccharide from a rough mutant Rc Salmonella minnesota R5 was extracted from bacteria grown at $37{ }^{\circ} \mathrm{C}$ by the phenol/chloroform/petrol ether method, purified, and lyophilized. Free lipid A was isolated by acetate buffer treatment of the LPS. After isolation, lipid A was purified and converted to the triethylamine salt form. The known chemical structure of lipid A was confirmed by the analysis of the amount of glucosamine, total organic phosphate, and the distribution of the fatty acid residues applying standard procedures. The amount of 2-keto-3-deoxyoctonate (Kdo) never exceeded $5 \%$. Additionally, the homogeneity of the endotoxin samples was checked with MALDI-TOF mass spectroscopy.

Pentaacyl lipid A according to a partial structure of Chlamydia trachomatis-lipid A was synthesized according to recently published work [15].

\section{Hemoglobin}

Hemoglobin was purified from fetal ovine blood as described earlier [16].

\section{Sample Preparation}

The lipid samples were usually prepared as aqueous dispersions at $85 \%$ water content using $20 \mathrm{mM}$ HEPES pH 7.0. For this, the lipids were suspended directly in buffer, temperature-cycled several times between 5 and $70{ }^{\circ} \mathrm{C}$, and then stored at $4{ }^{\circ} \mathrm{C}$ for at least $12 \mathrm{~h}$ before measurement. This procedure gave the most reproducible results. Hb dissolved in HEPES was added in appropriate amounts, and the mixture further incubated at $37^{\circ} \mathrm{C}$ for $15 \mathrm{~min}$.

\section{FTIR Spectroscopy}

The infrared spectroscopic measurements were performed on an IFS-55 spectrometer (Bruker, Karlsruhe, Germany). The lipid samples were placed in a $\mathrm{CaF}_{2}$ cuvette with a $12.5 \mu \mathrm{m}$ teflon spacer. Temperature-scans were performed automatically from 10 to $70{ }^{\circ} \mathrm{C}$ with a heating rate of 0.6 ${ }^{\circ} \mathrm{C} / \mathrm{min}$. Every $3{ }^{\circ} \mathrm{C}, 50$ interferograms were accumulated, apodized, Fourier transformed, and converted to absorbance spectra.

\section{Freeze-Fracture Electron Microscopy}

The measurements were done as recently described [17]. Briefly, a small amount of the samples was sandwiched between two copper profiles as used for the double-replica technique and frozen by plunging the sandwiches immediately into liquefied ethane-propane-mixture cooled in liquid nitrogen. Fracturing and replication were performed at -150 ${ }^{\circ} \mathrm{C}$ in a BAF 400T freeze-fracture device (BAL-TEC, Balzers, Liechtenstein) equipped with electron guns and a film sheet thickness monitor. For replication $\mathrm{Pt}(\mathrm{C})$ was evaporated under an angle of $35^{\circ}$ and $\mathrm{C}$ under $90^{\circ}$. The replicas were placed on copper grids, cleaned with a chloroform-methanol mixture, and examined in an EM 900 electron microscope (Zeiss, Oberkochen, Germany).

\section{Small-Angle X-Ray Diffraction}

$\mathrm{X}$-ray diffraction measurements were performed at the European Molecular Biology Laboratory (EMBL) outstation at the Hamburg synchrotron radiation facility HASYLAB using the SAXS camera X33 essentially as described recently [12]. Diffraction patterns in the range of the scattering vector $0.1<\mathrm{s}<1.0 \mathrm{~nm}^{-1}(\mathrm{~s}=2 \sin \theta / \lambda, 2 \theta$ scattering angle and $\lambda$ the wavelength $=0.15 \mathrm{~nm}$ ) were recorded at $40^{\circ} \mathrm{C}$ with exposure times of $1 \mathrm{~min}$ using an image plate detector with online readout (MAR345, MarResearch, Norderstedt/Germany). [18]. The lipid concentrations were in all cases $20 \mathrm{mM}$.

The s-axis was calibrated with Ag-behenate (periodicity $=58.4 \mathrm{~nm}$ ). The diffraction patterns were evaluated as described previously, assigning the spacing ratios of the main scattering maxima to defined three-dimensional structures. The lamellar and cubic structures are the most relevant here. The following features characterize the supramolecular structure:

(1) Lamellar: The reflections are grouped in equidistant ratios, i.e., $1,1 / 2,1 / 3,1 / 4$, etc. of the lamellar repeat distance $\mathrm{d}_{1}$;

(2) Cubic: The different space groups of these nonlamellar three-dimensional structures differ in the ratio of their spacings. The relation between reciprocal spacing $\mathrm{S}_{\mathrm{hkl}}=$ $1 / \mathrm{dhkl}$ and lattice constant $\mathrm{a}$ is

$\mathrm{S}_{\mathrm{hkl}}=\left[\left(\mathrm{h}^{2}+\mathrm{k}^{2}+\mathrm{l}^{2}\right) / \mathrm{a}\right]^{1 / 2}$

(hkl = Miller indices of the corresponding set of plane).

\section{Cytokine Production in Human Mononuclear Cells}

Mononuclear cells (MNC) were isolated from heparinized blood of healthy donors as described previously [14]. The cells were resuspended in medium (RPMI 1640) and their number was equilibrated at $5 \times 10^{6}$ cells $/ \mathrm{ml}$. For stimulation, $200 \mu \mathrm{MNC}\left(1 \times 10^{2}\right.$ cells) were transferred into each well of a 96-well culture plate. Mixtures of the lipids with $\mathrm{Hb}$ were incubated for $30 \mathrm{~min}$ at $37{ }^{\circ} \mathrm{C}$, and added to the cultures at $20 \mu \mathrm{l}$ per well. The cultures were incubated for $4 \mathrm{~h}$ at $37^{\circ} \mathrm{C}$ under $5 \% \mathrm{CO}_{2}$. Supernatants were collected after centrifugation of the culture plates for $10 \mathrm{~min}$ at $400 \mathrm{x} \mathrm{g}$ and stored at $-20{ }^{\circ} \mathrm{C}$ until determination of $\mathrm{TNF} \alpha$ content. Immunological determination of TNF $\alpha$ was carried out in a Sandwich ELISA using a monoclonal antibody against TNF (clone $6 \mathrm{~b}$ from Intex $\mathrm{AG}$, Switzerland) and was described earlier in detail [19].

\section{RESULTS}

Previously it was shown that $\mathrm{Hb}$ causes a disaggregation of LPS Re structures [17]. To continue the examination of 
this phenomenon we applied freeze-fracture electron microscopy to examine whether this represents a general behaviour. Mutant LPS Rc (R5 from $S$. minnesota) was investigated in the absence and presence of $\mathrm{sHb}$. As may be seen from Fig. $\mathbf{1 A}$, in absence of $\mathrm{sHb}$ the electron micrographs are indicative of large liposome-like structures and extensive planar bilayer lamellae in the size range of some hundred $\mathrm{nm}$. The structures can form (oligo)lamellar stacks, but also show vesicle-like morphologies. In the presence of $\mathrm{sHb}$, the picture completely changes (Fig. 1B). Very small disc-like fragments often forming stacks, a few number of small vesicles, and small particle-like structures appear (see arrows). Clearly, there is a dramatic decrease in average size.

The enhancement of the cytokine-inducing capacity of $\mathrm{Hb}$ was proven using various LPS preparations [10, 20-21]. It was therefore of great interest whether other pathogenicity factors, which were proven to represent endotoxic mimetics, exhibit a similar behaviour. For this we selected the phospholipid-like structure ER-803022, a synthetic compound with six acyl chain residues as hydrophobic moiety and two phosphates and a serine-like backbone [22, 23], and the synthetic bacterial lipopeptide $\mathrm{Pam}_{3} \mathrm{CSK}_{4}$ [14]. ER-803022 was added to human mononuclear cells (MNC) at concentrations of 10,100 , and $1000 \mathrm{ng} / \mathrm{ml}$ in the absence and presence of $\mathrm{sHb}$ at three different concentrations ([ER-803022]:[sHb] 1:10, 1:100, and 1:1000 weight ratio) (Fig. 2). The data for the pure compound shows a concentration-dependent decrease of the TNF $\alpha$-inducing capacity from approximately 1400 over 800 to $300 \mathrm{pg} / \mathrm{ml} \mathrm{TNF} \alpha$. In the presence of $\mathrm{Hb}$, there is a strong increase in the cytokine induction, even at [ER-803022]:[sHb] 1:10 weight\% except for the ER-803022 concentration of $1000 \mathrm{ng} / \mathrm{ml}$.

The synthetic lipopeptide $\mathrm{Pam}_{3} \mathrm{CSK}_{4}$, derived from Braun's lipoprotein, expressing endotoxin-typical activity, was also monitored with respect to a possible increase of the cytokine-inducing capacity. The data presented in Fig. 3 shows a clear enhancement of the TNF $\alpha$ stimulation in human mononuclear cells, at least for an excess of $\left[\mathrm{Pam}_{3} \mathrm{CSK}_{4}\right]$ : $[\mathrm{sHb}]$ of $100: 1 \mathrm{w} / \mathrm{w}$.

A

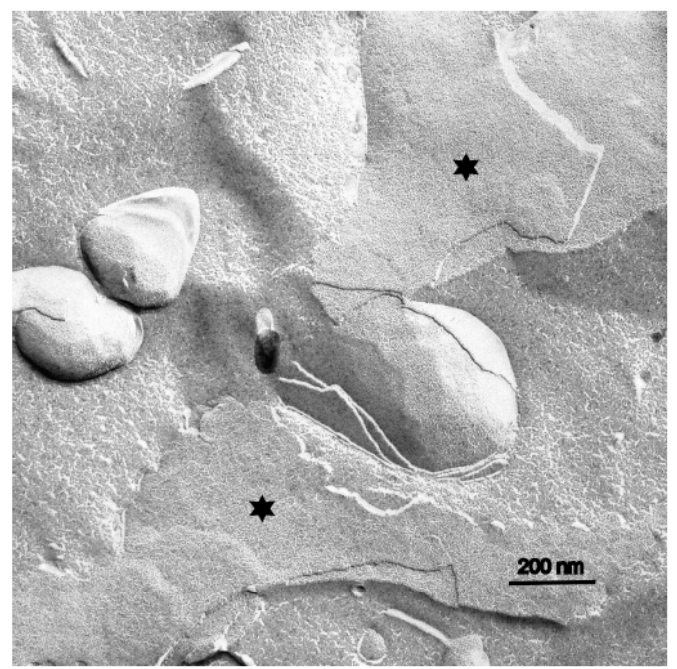

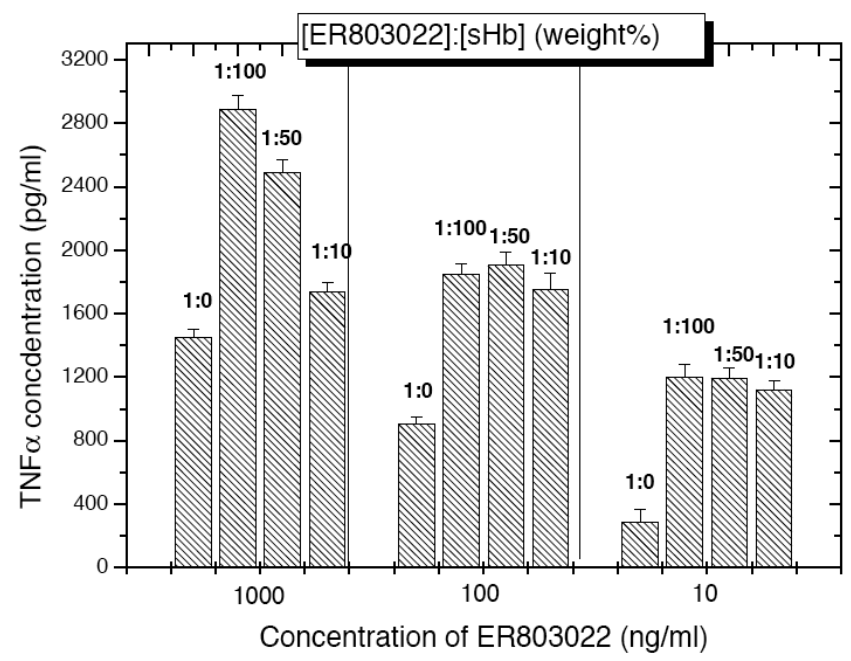

Fig. (2). Induction of tumor-necrosis-factor $\alpha$ (TNF $\alpha$ ) by synthetic phospholipid-like compound ER-803022 in the presence of various concentrations of $\mathrm{sHb}$. Pure $\mathrm{sHb}$ does not show any activity (data not shown). The error comes from the determination of TNF $\alpha$ in duplicate at two different dilutions by averaging these values.

It was published that a pentaacyl lipid A from E. coli, which is biologically inactive in pure form corresponding to a multilamellar aggregate structure, was converted into an active cubic aggregate conformation by the addition of an $\alpha \alpha$-cross-linked preparation of human hemoglobin concomitant with high cytokine-inducing capacity [13]. To check the general validity of this observation, we tested a particular preparation of synthetic pentaacyl lipid A (pLA) from Chlamydia trachomatis. This pLA is characterized by longer acyl chains (C-18 to C-21) as compared to classical lipid A from E. coli, and was found to induce no cytokines from immune cells [24]. In Fig. 4, the results are indicative of a concentration-dependent increase in TNF $\alpha$-inducing capacity induced by $\mathrm{Hb}$. In particular, at the highest $\mathrm{Hb}$ concentration $(300 \mu \mathrm{g})$ at all pLA concentrations $(3,30$, and 300 $\mathrm{ng} / \mathrm{ml}$ ) the activity is nearly as high as that of the control LPS R60 at $15 \mathrm{ng} / \mathrm{ml}$.

B

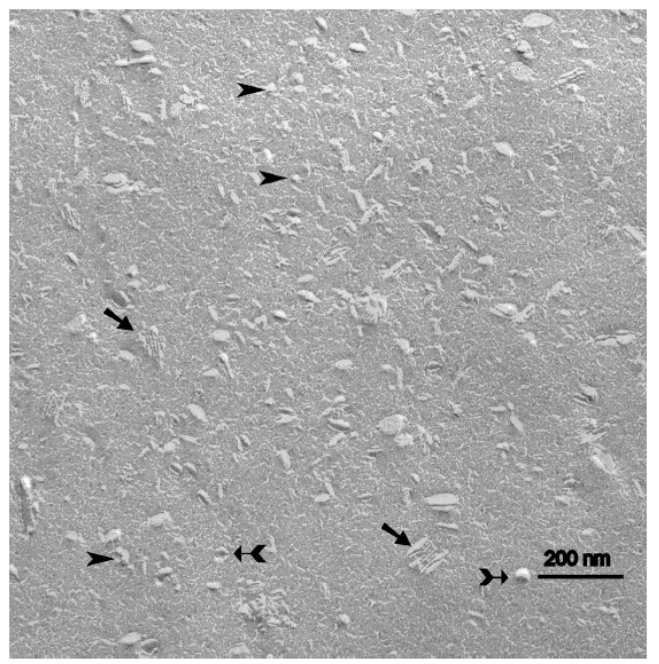

Fig. (1). Freeze-fracture electron micrographs of (A) $5 \mathrm{mg}$ LPS Rc from Salmonella minnesota strain R5 indicate large vesicular structures, and (B) in the presence of $2 \mathrm{mg} \mathrm{sHb}$ (B) small clod-like structures and single small vesicles (see arrows). 


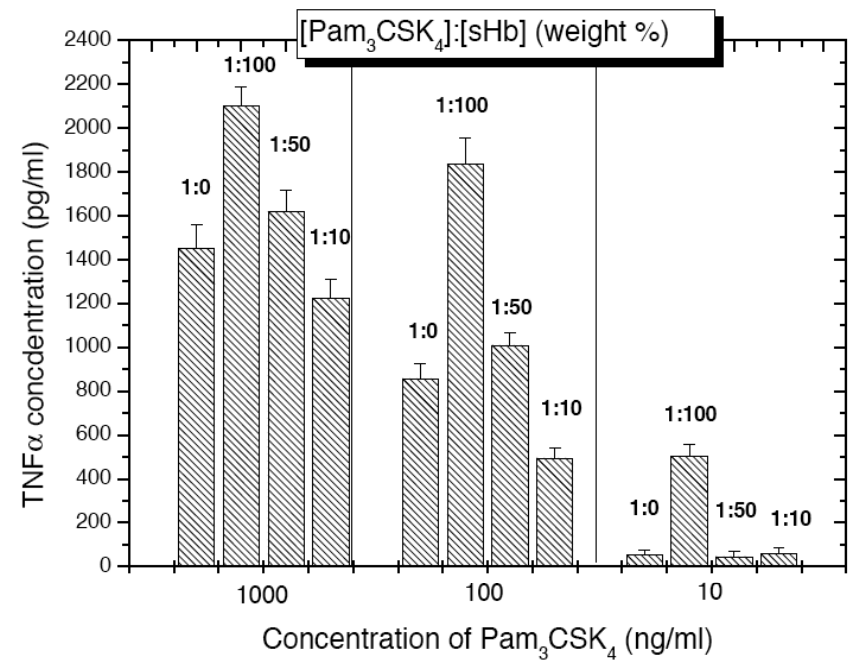

Fig. (3). Induction of tumor-necrosis-factor $\alpha$ (TNF $\alpha)$ by synthetic lipopeptide $\mathrm{Pam}_{3} \mathrm{CSK}_{4}$ in the presence of various concentrations of $\mathrm{sHb}$. Pure $\mathrm{sHb}$ does not show any activity (data not shown). The error comes from the determination of TNF $\alpha$ in duplicate at two different dilutions by averaging these values.

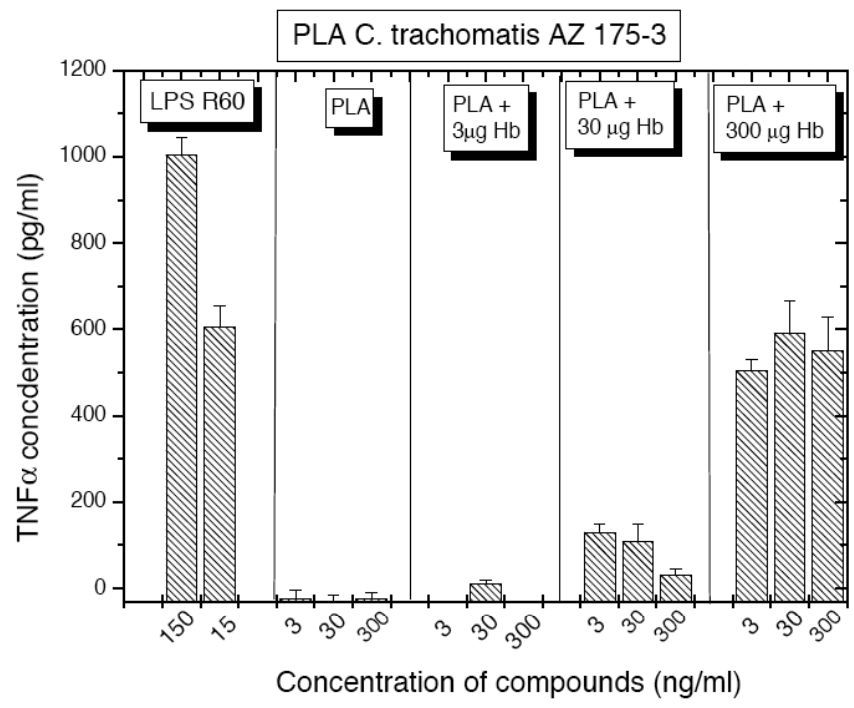

Fig. (4). Induction of tumor-necrosis-factor $\alpha$ (TNF $\alpha$ ) by synthetic pentaacyl lipid A corresponding to a fraction of Chlamydia trachomatis-lipid A in the presence of various concentrations of $\mathrm{sHb}$. Pure $\mathrm{sHb}$ does not show any activity up to the highest concentrations used $(300 \mu \mathrm{g}$, data not shown). The error comes from the determination of TNF $\alpha$ in duplicate at two different dilutions by averaging these values.

Experiments to obtain a better understanding of the behaviour of the gel to liquid crystalline phase transition and the aggregate structure for the synthetic lipopeptide $\mathrm{Pam}_{3}$ $\mathrm{CSK}_{4}$ were also performed. Fourier-transform infrared spectroscopy (FTIR) was applied for the elucidation of the phase behaviour by analysing the peak position of the symmetric stretching vibrational band of the methylene groups [25]. As shown in Fig. 5, pure $\mathrm{Pam}_{3} \mathrm{CSK}_{4}$ has a phase transition around $35{ }^{\circ} \mathrm{C}$ in accordance with the published value [14], which decreases in the presence of $\mathrm{Hb}$, especially at the concentration ratio $\left[\mathrm{Pam}_{3} \mathrm{CSK}_{4}\right]:[\mathrm{Hb}]$ 1:0.2 molar. Concomi- tantly, there is an overall increase in the wavenumber values corresponding to an increase in fluidity. A similar increase of the wavenumber values induced by $\mathrm{Hb}$ as compared to the pure compound was also observed for ER-803022 (data not shown), which melts around $15^{\circ} \mathrm{C}$ in accordance to former data [23].

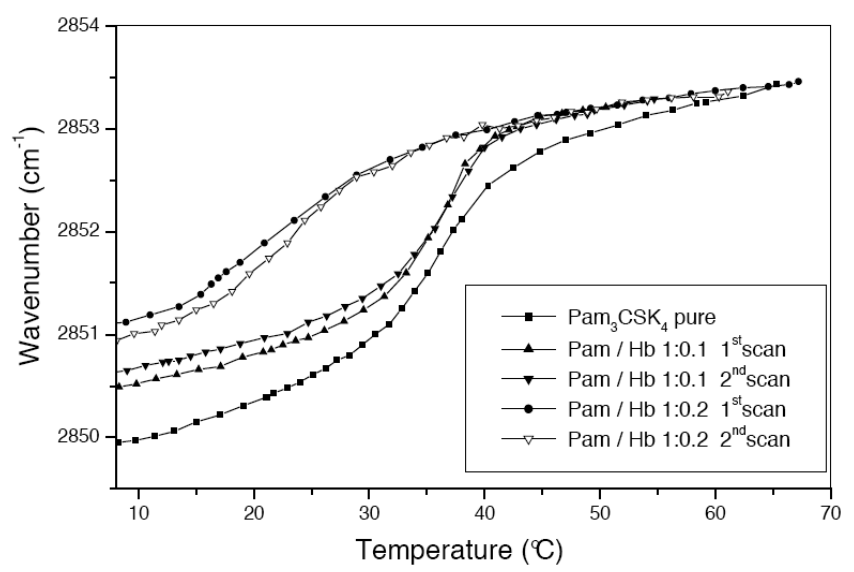

Fig. (5). Peak position of the symmetric stretching vibrational band of the methylene groups versus temperature indicating the gel to liquid crystalline phase transition of the hydrocarbon chains of a 10 $\mathrm{mM}$ preparation of $\mathrm{Pam}_{3} \mathrm{CSK}_{4}$ in the absence and presence of $\mathrm{sHb}$ at $\left[\mathrm{Pam}_{3} \mathrm{CSK}_{4}\right]:[\mathrm{Hb}]$ 1:0.1 and 1:0.2 molar.

The aggregate structures of lipid A and LPS, which usually are unilamellar or mixed unilamellar/cubic [26-28], are converted into pure cubic structures in the presence of $\mathrm{Hb}$ $[10,12]$. To test whether a similar behaviour is observed for $\mathrm{Pam}_{3} \mathrm{CSK}_{4}$, small-angle X-ray scattering (SAXS) was applied for a $\left[\mathrm{Pam}_{3} \mathrm{CSK}_{4}\right]:[\mathrm{sHb}]$ 1:5 weight $\%$ preparation. There is evidence that the aggregate structure of $\mathrm{Pam}_{3} \mathrm{CSK}_{4}$ alone is already cubic, but weakly expressed [14]. The data in Fig. 5, obtained at $40{ }^{\circ} \mathrm{C}$ and $90 \%$ water content, shows a complex diffraction pattern. However, the reflections at 6.51 , $5.29,3.25$, and $2.17 \mathrm{~nm}$ are $1 / \sqrt{ } 2,1 / \sqrt{ } 3,1 / \sqrt{ } 8$, and $1 / \sqrt{ } 18$ of a periodicity at $9.2 \mathrm{~nm}$, and thus this pattern corresponds to a cubic structure of space group $\mathrm{Q}^{224}$. The remaining reflections cannot be assigned to a particular structure. $\mathrm{Q}^{224}$ was found to play an essential role for endotoxically active lipid A structures $[26,29]$ and this behaviour can now be generalized for non-lipid A/LPS preparations.

\section{DISCUSSION}

It is well known that free hemoglobin enhances the production of tumor necrosis factor- $\alpha$ (TNF $\alpha$ ) induced by LPS in human mononuclear cells [20, 30, 31], and also amplifies the rate of mortality caused by free LPS in rats [9]. This is a severe problem due to the potential of endotoxin contamination of $\mathrm{Hb}$ in blood substitution products (erythrocyte substitute) [20], and therefore represents a major barrier for the successful use of cell-free hemoglobin $(\mathrm{Hb})$ as an oxygen carrier in humans.

We showed previously that the type of supramolecular aggregate structures determine the biological activity of enterobacterial hexaacylated LPS and lipid A, and of pentaacylated LPS and lipid A from E. coli $[27,32]$. The former hexaacylated compounds adopt mixed unilamellar/cubic aggre- 
gate structures that are predicted to have high bioactivity, while the latter pentaacylated compounds adopt a multilamellar structure that are predicted to have low or no bioactivity. In the presence of $\mathrm{Hb}$ or partial structures thereof, like the $\alpha$-chain and the heme-free sample [17], these aggregate structures are converted into those with a preference for a pure three-dimensional cubic symmetry $[10,12,13]$ as for example $\mathrm{Q}^{224}$, which were shown to be the prototype of bioactive aggregate structure of endotoxins [32].

Previously we demonstrated this phenomenon in cases where endotoxins, lipid A and deep rough mutant LPS Re, were investigated. Here, we extended these measurements by using LPS with a longer carbohydrate chain as well as pathogenicity factors with a completely different chemical structure, which were found to exert high endotoxin-typical biological activity.

LPS Rc forms - due to its amphipathic character as other LPS - spontaneously aggregates in shape of large vesicular structures, expanded bilayer lamellae and membrane stacks (Fig. 1A). These structures have size distributions of some hundred $\mathrm{nm}$. After addition of $\mathrm{sHb}$, vesicles, if at all observed, are much smaller and have a strongly reduced amount. There are a lot of small disc-like bilayer fragments often forming stacks and numerous particle-like structures and fine granules. Some of the particles might represent small $\mathrm{Hb}$ aggregates (Fig. 1B). These data are in accordance with data from Roth et al. [11] who demonstrated also clear changes in electron micrographs after addition of $\mathrm{Hb}$ compatible with a disaggregation.

D'Agnillo [33] has studied the effect of various Hb structures and LPS on apoptosis, and found only in the absence of serum any effect. These data were interpreted by an effect of redox active $\mathrm{Hb}$, driven by the low level of oxidative stress, thus exacerbating the LPS-induced apoptosis. Their interpretation would not afford a direct interaction of LPS with $\mathrm{Hb}$, however, the effects studied here take place also in the absence of serum and, furthermore, an LPS-enhancing effect is also observed for the hem-free compound and the single $\alpha$ and $\gamma$-chains [16].

Summarizing the present data, it now can be generalized that a reduction of the sizes of the endotoxin aggregates is directly connected with an increase in bioactivity. Moreover, from the biological data presented here (Figs. 2-4) it becomes clear that the activity-enhancing ability of $\mathrm{Hb}$ is not restricted to enterobacterial endotoxins, but corresponds to a general property of this red blood cell protein concerning amphiphilic bacterial virulence factors that are completely different in their primary chemical structures. Therefore, it can be assumed that the same interaction mechanisms between these compounds and the cell surface of immunocompetent cells leads to cell activation. In particular, the strong tendency for cubic inverted aggregate structures of space group $\mathrm{Q}^{224}$ (Fig. 6) is a strong evidence for the importance of aggregates as biologically active units, as described previously for pure endotoxins $[34,35]$. It has been shown in fluorescence resonance energy-transfer (FRET) experiments that such aggregates, either alone or in the presence of binding proteins such as lipopolysaccharide-binding protein (LBP), incorporate into phospholipid liposomes correspond-

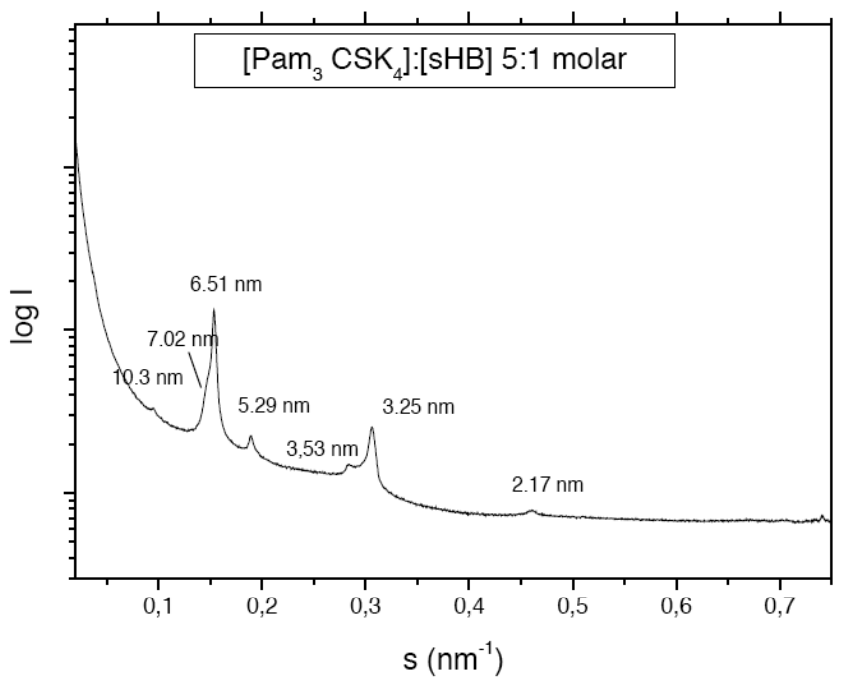

Fig. (6). Small-angle X-ray scattering pattern of $0.6 \mathrm{mg} \mathrm{Pam}{ }_{3} \mathrm{CSK}_{4}$ in the presence of $3 \mathrm{mg} \mathrm{sHb}$ presented as logarithm of the scattering intensity versus scattering vector $\mathrm{s}(\mathrm{s}=1 / \mathrm{d}, \mathrm{d}=$ lattice spacing, $\mathrm{s}=2$ $\sin \theta / \lambda, \theta=$ scattering angle, $\lambda=$ wavelength $=0.15 \mathrm{~nm})$.

ing to the composition of macrophage membranes [35]. In the membrane, these non-lamellar aggregates represent a strong disturbance of the membrane architecture, and are thus able to cause a conformational change of relevant membrane proteins such as CD14 and TLR4/MD2 [36, 37] leading to cell activation.

There are also papers in which LPS monomers are described as endotoxically active units [38]. In this context, also the recent paper by Jin et al. [39] may be seen who could co-crystallize a single triacylated lipopeptide with a TLR1/TLR2 construct (in the absence of the membrane anchor). In our context, however, a monomer as biologically unit makes no sense. The presented data unequivocally show a change of the aggregate structure when adding $\mathrm{Hb}$, whereas the molecular conformation of a monomer alone is not touched.

It is interesting that the phase transition behaviour of $\mathrm{Pam}_{3} \mathrm{CSK}_{4}$ (Fig. 5) is indicative of a fluidising effect of $\mathrm{Hb}$ on lipid packing. This behaviour was much less expressed for enterobacterial lipid A or LPS Re [12], but in some cases was also observed for these compounds (unpublished data). The reason for this unequivocal behaviour presently remains unclear and will be investigated in future.

The strong increase of the cytokine-inducing capacity of the "inactive" pentaacylated lipid A from C. trachomatis, (Fig. 4, see also [24]), after the addition of sHb corresponds to previous observations where endotoxically inactive pentaacyl LPS from E. coli, which in its pure form has a multilamellar structure, is converted into a physiologically bioactive conformation by the addition of $\alpha \alpha$-cross-linked $\mathrm{Hb}$ [13]. Therefore, the ability of $\mathrm{Hb}$ to influence the molecular conformation does not depend on the particular acylation patterns of the lipid A moieties, which differ significantly for the two pentaacyl compounds. More important is the basic aggregate structure, which can be converted into an active form as stated above. 


\section{ACKNOWLEDGEMENTS}

The authors gratefully acknowledge the financial support of the 'Clinique La Prairie', Montreux, Switzerland. We thank also G. von Busse and K. Stephan for support in various infrared and biological experiments, and R. Kaiser for excellent technical work.

\section{REFERENCE}

[1] Rietschel E.Th.; Kirikae T.; Schade F.U.; Mamat U.; Schmidt G.; Loppnow H.; Ulmer A.J.; Zähringer U.; Seydel U.; Di Padova F.; Schreier M.; Brade H. FASEB J., 1994, 8, 217.

[2] Rietschel E.T.; Brade H.; Holst O.; Brade L.; Müller-Loennies S.; Mamat U.; Zähringer U.; Beckmann F.; Seydel U.; Brandenburg K.; Ulmer A.J.; Mattern T.; Heine H.; Schletter J.; Hauschildt S.; Loppnow H.; Schönbeck U.; Flad H.-D.; Schade U.F.; Di Padova F.; Kusumoto S.; Schumann R.R. Curr. Top. Microbiol. Immunol., 1996, 216,39

[3] Kitchens R.L.; Wolfbauer G.; Albers J.J.; Munford R.S. J. Biol. Chem., 1999, 274, 34116.

[4] Pristovsek P. and Kidric J. Curr. Top. Med. Chem., 2004, 4, 1185.

[5] Kaca W.; Roth R.I.; Ziolkowski A.; Levin J. J. Endotoxin Res., 1994, $1,243$.

[6] Roth R.I. and Kaca W. Biomater. Artif. Cells Immobilization Biotechnol., 1994, 22, 387.

[7] Roth R.I.; Kaca W.; Levin J. Prog. Clin. Biol. Res., 1994, 388, 161.

[8] Roth R.J.; Levin J., in Endotoxin in health and disease, Brade, Opal, Vogel, and Morrison. Eds.; Marcel Dekker New York 1999; pp. 389-401.

[9] Goff J.M.; Jackson M.R.; Taher M.; Cutting M.A.; Alving B.M.; Krishnamurti C. Artif. Cells Blood Substit. Immobil. Biotechnol., 1999, 27, 11.

[10] Jürgens G.; Müller M.; Koch M.H.J.; Brandenburg K. Eur. J. Bio., 2001, 268, 4233.

[11] Roth R.I. J. Endotoxin Research, 1996, 3, 361.

[12] Howe J.; Hammer M.; Alexander C.; Rossle M.; Fournier K.; Mach J.P.; Waelli T.; Gorczynski R.M.; Ulmer A.J.; Zahringer U.; Rietschel E.T.; Brandenburg K. Med. Chem., 2007, 3, 13.

[13] Brandenburg K.; Garidel P.; Andrä J.; Jürgens G.; Müller M.; Blume A.; Koch M.H.J.; Levin J. J. Biol. Chem., 2003, 278, 47660.

[14] Schromm A.B.; Howe J.; Ulmer A.J.; Wiesmuller K.H.; Seyberth T.; Jung G.; Rössle M.; Koch M.H.J.; Gutsmann T.; Brandenburg K. J. Biol. Chem., 2007, 282, 11030.

[15] Zamyatina A.; Sekljic H.; Brade H.; Kosma P. Tetrahedron, 2004, $60,12113$.

[16] Gorczynski R.M.; Alexander C.; Bessler W.; Fournier K.; Hoffmann P.; Mach, J.P.;Manuel J.; Ramakrishna V.; Rietschel
E.T.; Song L.; Waelli T.; Westphal O.; Zähringer U. Int. Immunopharmacol., 2004, 4, 1859.

[17] Howe, J., J.; Garidel P.; Roessle M.; Richter W.; Alexander C., Fournier K.; Mach, J.P.; Waelli T.; Gorczynski R.M.; Ulmer A.J.; Zähringer U.; Hartmann A.; Rietschel E.Th.; Brandenburg K. $J$. Endotoxin Res., 2008 (in press).

[18] Roessle, M.W.; Klaering R.; Ristau U.; Robrahn B.Jahn,D Gehrmann T., Konar, Round A.;FiedlerS.; Hermes C.; SvergunD. J. Appl. Cryst., 2007, 40, s190.

[19] Mueller M.; Brandenburg K.; Dedrick R.; Schromm A.B.; Seydel U. J. Immunol., 2005, 174, 1091.

[20] Su D.; Roth R.I.; Yoshida M.; Levin J. Infect. Immun., 1997, 65, 1258.

[21] Su D.H.; Roth R.I.; Levin J. Crit. Care Med., 1999, 27, 771.

[22] Seydel U.; Hawkins L.; Schromm A.B.; Heine H.; Scheel O.; Koch M.H.; Brandenburg K. Eur. J. Immunol., 2003, 33, 1586.

[23] Brandenburg K.; Hawkins L.; Garidel P.; Andrä J.; Müller M.; Heine H.; Koch M.H.J.; Seydel U. Biochemistry, 2004, 43, 4039.

[24] Heine H.; Gronow S.; Zamyatina A.; Kosma P.; Brade H. J. Endotoxin. Res., 2007, 13, 126.

[25] Brandenburg K. and Seydel U. Chem. Phys. Lipids 1998, 96, 23.

[26] Brandenburg K.; Koch M.H.J.; Seydel U. J. Struct. Biol., 1990, 105,11 .

[27] Brandenburg K.; Mayer, H.; Koch, M.H.J.; Weckesser, J.; Rietschel, E.Th.; Seydel, U. Eur J. Biochem. 1993, 218, 555.

[28] Seydel U.; Koch M.H.J.; Brandenburg K. J. Struct. Biol., 1993, 110, 232.

[29] Brandenburg K.; Richter W.; Koch M.H.J.; Meyer H.W.; Seydel U. Chem. Phys. Lipids 1998, 91, 53

[30] Carrillo E.H.; Gordon L.E.; Richardson J.D.; Polk H.C., Jr. J. Trauma, 2002, 52, 449.

[31] Kaca W. and Roth R. Biochim. Biophys. Acta, 1995, 1245, 49.

[32] Brandenburg K.; Andrä J.; Müller M.; Koch M.H.J.; Garidel P. Carbohydr. Res., 2003, 338, 2477.

[33] D'Agnillo. Am. J. Physiol. Heart Circ. Physiol., 2004, 287, H1875.

[34] Mueller M.; Lindner B.; Kusumoto S.; Fukase K.; Schromm A.B. Seydel U. J. Biol. Chem., 2004, 279, 26307.

[35] Gutsmann T.; Schromm A.B.; Koch M.H.J.; Kusumoto S.; Fukase K.; Oikawa M.; Seydel U.; Brandenburg K. Phys. Chem. Chem. Phys., 2000, 2, 4521.

[36] Tobias P.S.; Soldau K.; Gegner J.A.; Mintz D.; Ulevitch R.J. $J$. Biol. Chem., 1995, 270, 10482.

[37] Beutler B. Curr. Opin. Immunol., 2000, 12, 20

[38] Teghanemt A.; Prohinar P.; Gioannini T.L.; Weiss J.P. J. Biol. Chem., 2007,

[39] Jin M.S.; Kim S.E.; Heo J.Y.; Lee M.E.; Kim H.M.; Paik S.-G.; Lee H.; Lee, J.-O. Cell, 2007, 1071 